Supporting information

\title{
Hydrogen-Bonding-Driven Wettability Change of Colloidal Crystal Films: from Superhydrophobicity to Superhydrophilicity
}

\author{
Jingxia Wang, Junping $\mathrm{Hu}$, Yongqiang Wen, Yanlin Song, ${ }^{*}$ and Lei Jiang *
}

Synthesis of core-shell latex spheres: Monodispersed core-shell latex spheres of poly(styrene-methyl methacrylate-acrylic acid) (Poly(St-MMA-AA)), were prepared via batch emulsion polymerization as modified reported procedure ${ }^{11 \mathrm{a}, \mathrm{b}}$ except charging the emulsifier of sodium dodecyl benzene sulfonate(SDBS, $0.014 \mathrm{mmol}$ ) into the system. The synthetic procedure is similar to the literature Briefly, MMA (10.00mmol), AA (13.89 mmol) and St $(182.60 \mathrm{mmol})$ were dispersed in $100 \mathrm{~mL}$ water dissolved by minute amount of emulsifier of sodium dodecylbenzenesulfonate and buffer agent of ammonium bicarbonate (6.30 mmol). The reaction mixture was kept at $70{ }^{\circ} \mathrm{C}$ for $0.5 \mathrm{~h}$. Following the addition of aqueous solution of ammonium peroxodisulfate (APS, $2.12 \mathrm{mmol}$ ), the polymerization was carried out at $80{ }^{\circ} \mathrm{C}$ for $10 \mathrm{~h}$ with continuously stirring. The resulting latex spheres were used directly without purification, and the $\mathrm{pH}$ of the system is 6.0. The polydispersity of the latex spheres was about 0.005, which was detected by ZetaPALS BI-90plus (Brookhaven Instrument). The core-shell $^{12 a}$ morphology of latex spheres was characterized by H800 transmission electron microscopy (TEM) (JEM2010, Japan) as inserted in Figure 1(a).

Fabrication of colloidal crystals: The colloidal crystal films were prepared via vertical deposition method $^{12 b}$ on clean glass slides. The clean glass slides were vertically positioned in a vial containing the $\mathrm{P}(\mathrm{St}-\mathrm{MMA}-\mathrm{AA})$ colloidal suspensions with the concentration of 0.2 wt.- $\%$ at the temperature of $25^{\circ} \mathrm{C}$ and the humidity of $70 \%$ for ca. $48 \mathrm{~h}$. The $\mathrm{pH}$ of the latex suspension was varied from 6.0 to 12 by introducing $\mathrm{NH}_{3} \cdot \mathrm{H}_{2} \mathrm{O}$ into the latex suspension. And the $\mathrm{pH}$ of the original latex suspension is 6.0 . 
The switchable wettability of the films was controlled by alternatively exposing the film in the vapor of concentrated $\mathrm{NH}_{3} \cdot \mathrm{H}_{2} \mathrm{O}$ or $\mathrm{HCl}$ in a beaker covered by a closed glass chamber.

Characterization: Scanning electron microscopy (SEM) images were obtained with a field-emission scanning electron microscopic (JEOL JSM-6700, Japan). UV-Vis spectra were performed with a U-4100 UV-Vis Spectrometer (Hitachi, Japan). Water contact angle (CA) was measured on an OCA20 Contract-angle System (Dataphysics, Germany) at room temperature. The CA values were averages of five independent measurements. The advancing and receding angles were obtained by increasing or decreasign the drop volume until the three-phase boundarymoved over the surfaces, and the data of experimental result and relative error are taken directly from the instruments. A Nicolet Magna 750 FTIR spectrometer was used to investigate the chemical component of the colloidal crystal films by Attenuated total reflectance infrared spectroscopy (ATR-FTIR) mode. X-ray photoelectron spectroscopy data were obtained with an ESCALab220i-XL electron spectrometer from VG Scientific using 300W AlK $\alpha$ radiation. The base pressure was about $3 \times 10^{-9} \mathrm{mbar}$. The binding energies were referenced to the $\mathrm{C} 1 \mathrm{~s}$ line at $284.6 \mathrm{eV}$ from adventitious carbon. 


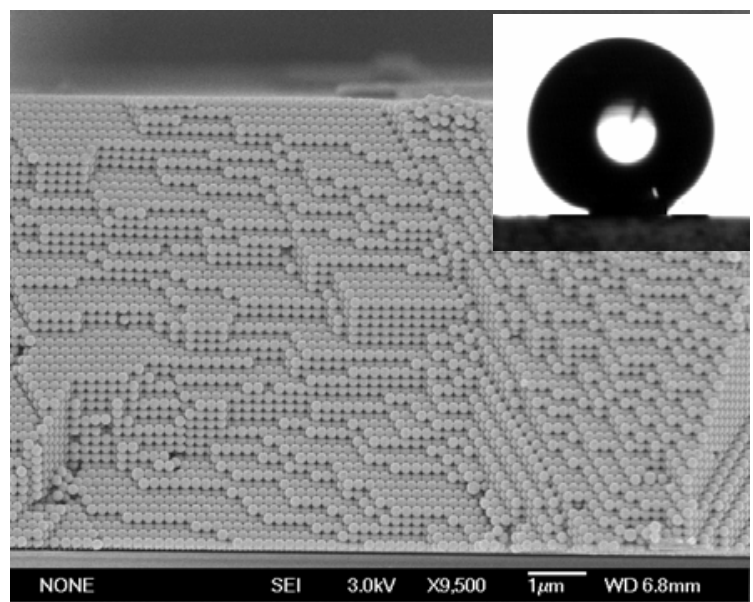

Figure S1: Side view of SEM image of the colloidal crystal film assembled from latex suspension with $\mathrm{pH}=6$ (inset: water droplet profile of relative water $\mathrm{CA}$ of $153^{\circ}$ ). The wettability of the cross-section is consistent with that of the top view, which indicates the film could keep superhydrophobicity even if its surface is worn. 

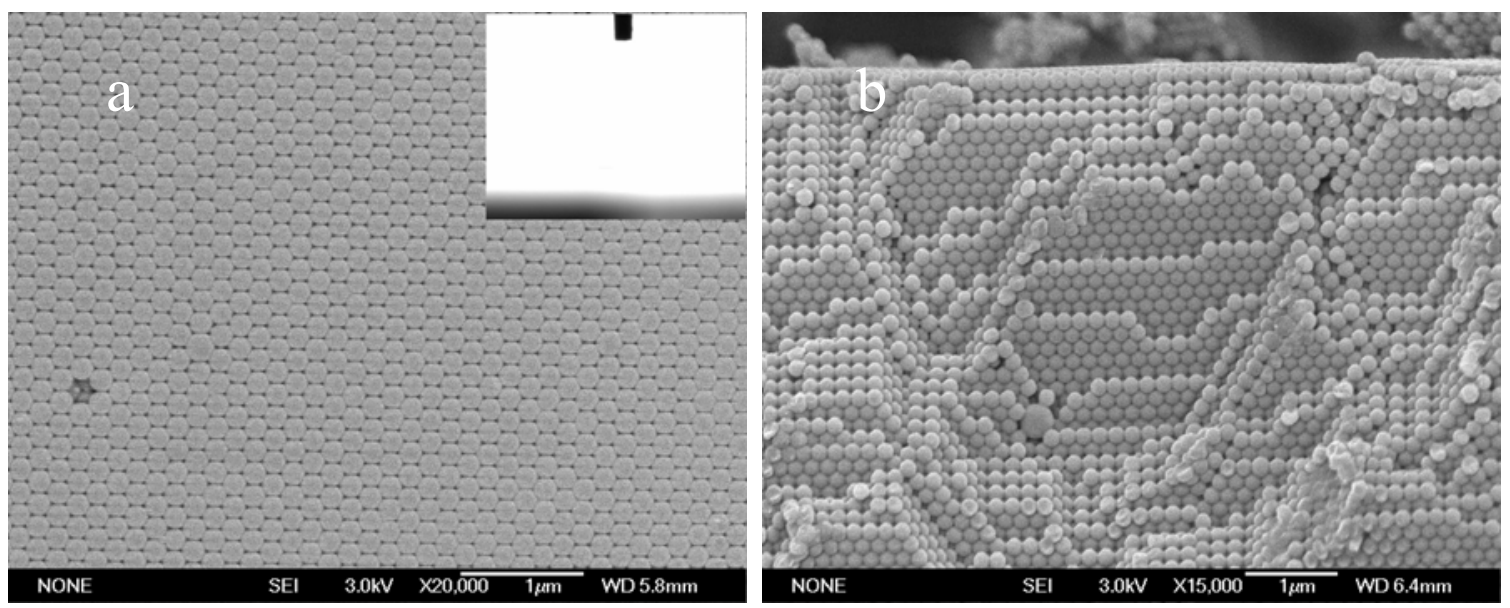

Figure S2: SEM images of the colloidal crystal film assembled from latex suspension with $\mathrm{pH}=12$, a) Top view (inset: water droplet profile of relative water $\mathrm{CA} \mathrm{of} 0^{\circ}$ ), b) Side view. The film shows superhydrophilicity with water CA of $0^{\circ}$ whether on the top or cross section. The result is contrast to the superhydrophobic film assembled when pH = 6 by same procedure. Additionally, little change is observed when comparing SEM images of the films assembled from latex suspension with $\mathrm{pH}$ of 6 and 12, which indicates the change of surface chemical composition plays a dominant role on the different wettability of the film. 


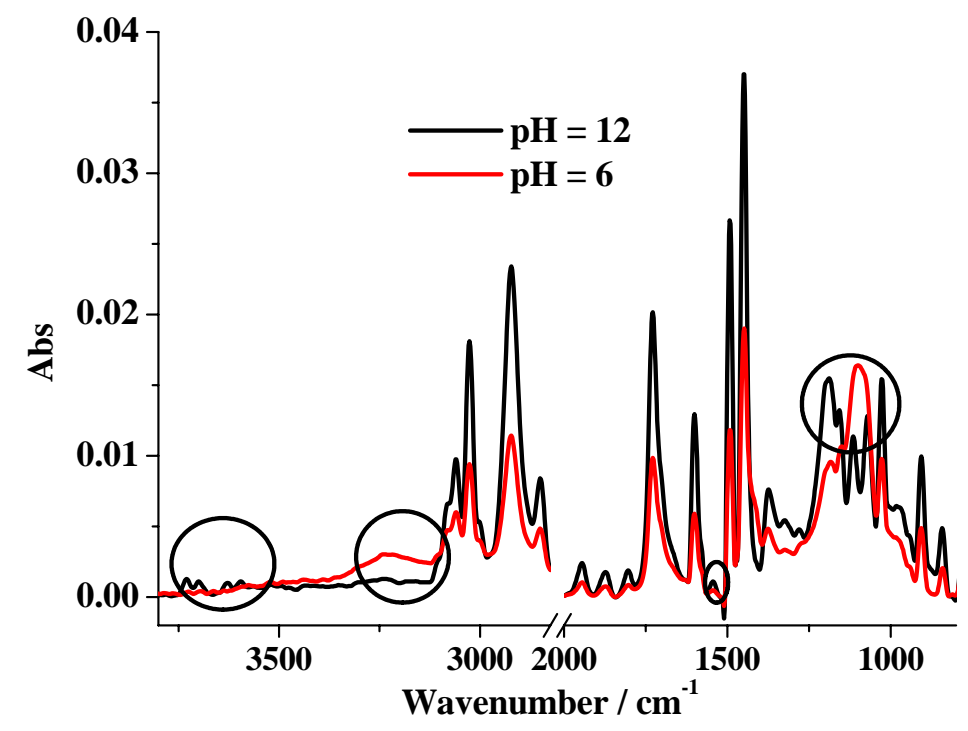

Figure S3: ATR-FTIR spectra of the colloidal crystal films assembled from latex suspension with pH 6 and 12. It can be seen that there are four characteristic peaks (noted by circles, the bands between $3600-3700 \mathrm{~cm}^{-1}$ could be assigned to the N-H stretching signal), which indicate the change of the surface chemical composition, i.e., the association between $\mathrm{SO}_{3} \mathrm{Na}^{+}$and $\mathrm{COOH}$ under different $\mathrm{pH}$. The result suggests the disappearance of hydrogen bonding after introducing $\mathrm{NH}_{3} \cdot \mathrm{H}_{2} \mathrm{O}$ into the latex suspension. As greatly affects the wettability change of the resulting films. 


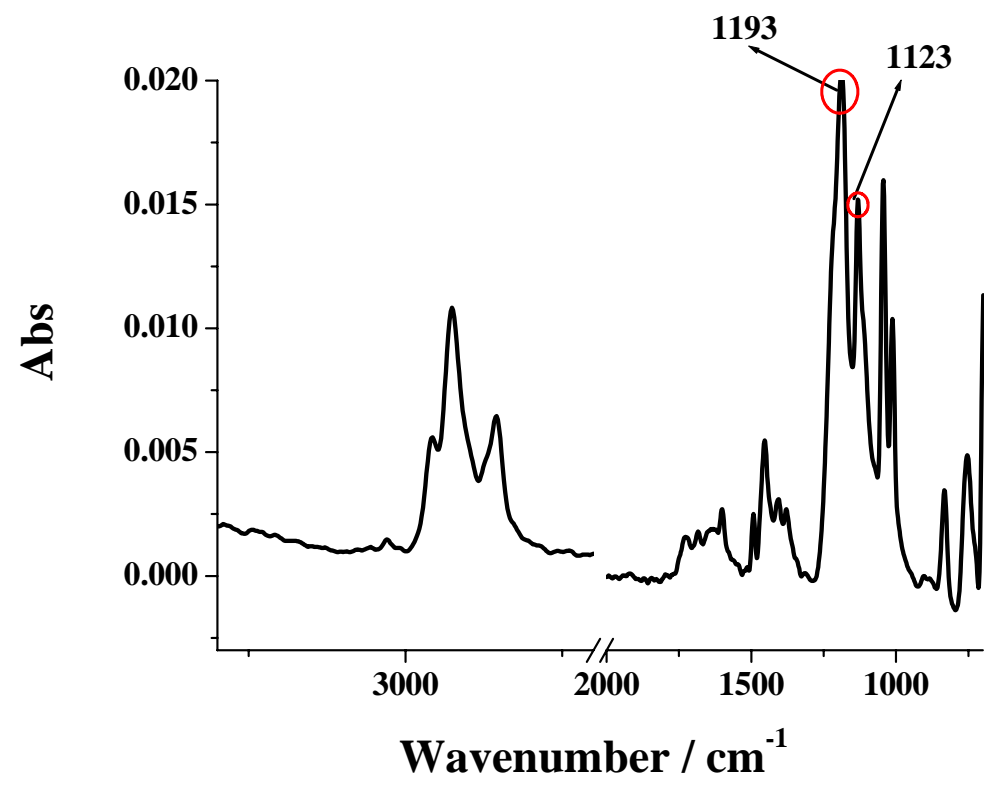

Figure S4: ATR-FTIR spectrum of SDBS. Main changes occur to the bands indicated by red circle for SDBS when varying the $\mathrm{pH}$ of the assembly latex suspension from 6.0 to 12.0. 


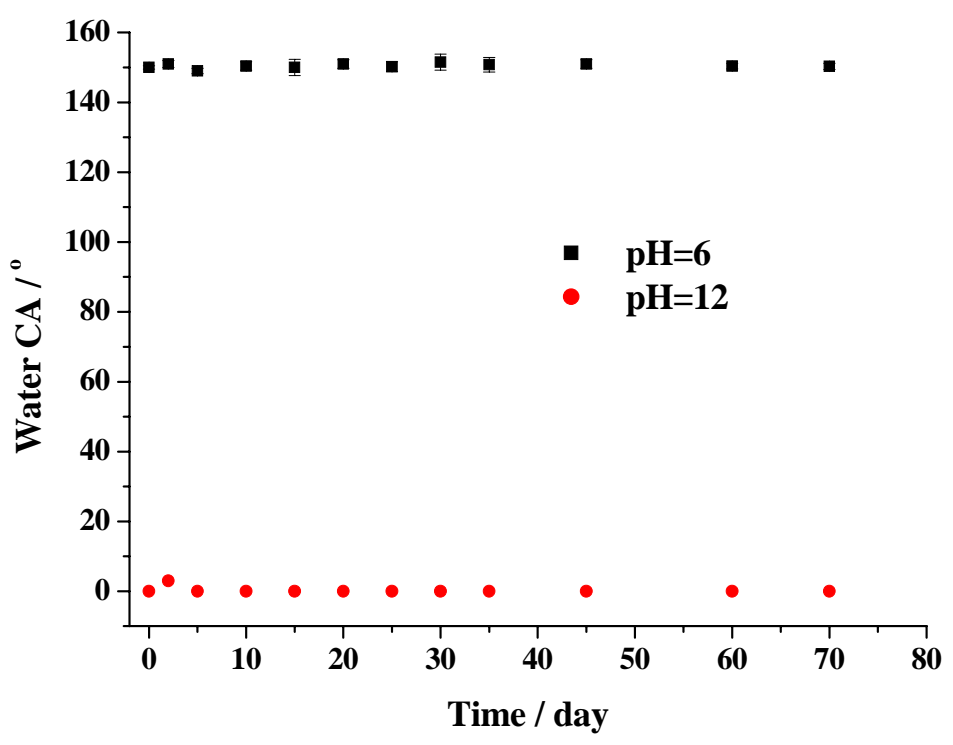

Figure S5: The relationship of water CA of the colloidal crystal films (assembled from latex suspensions with different $\mathrm{pH}$ ) and exposure time in air. The result shows that the films show good durability even if exposed in air for several months. 


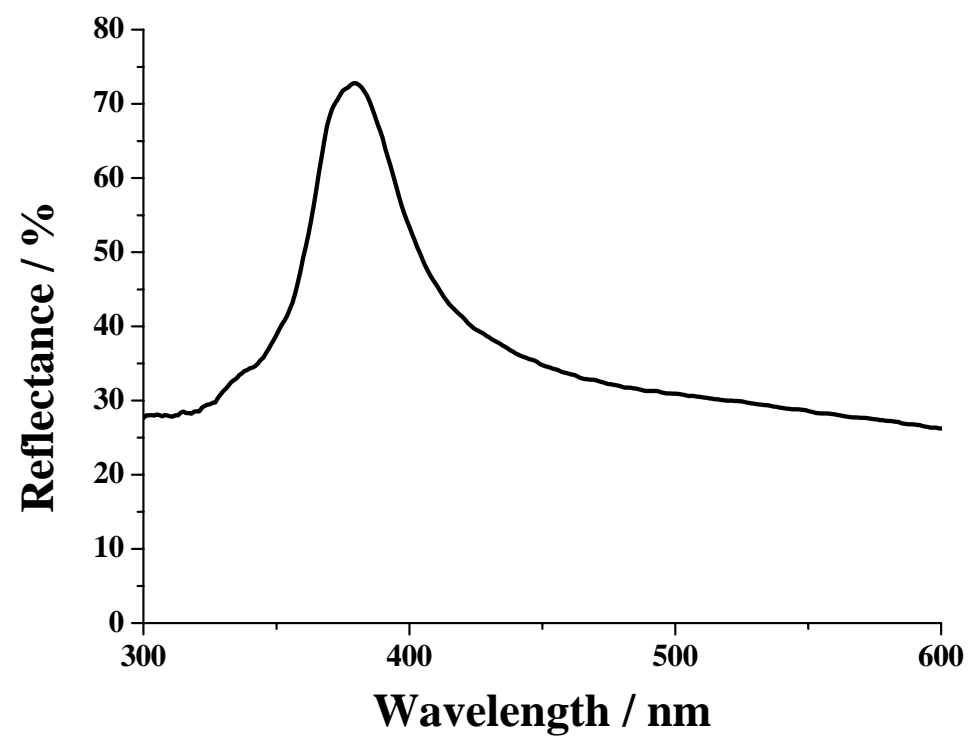

Figure S6: UV-Vis spectrum of the colloidal crystal film. The position of photonic band gap is $369 \mathrm{~nm}$. 


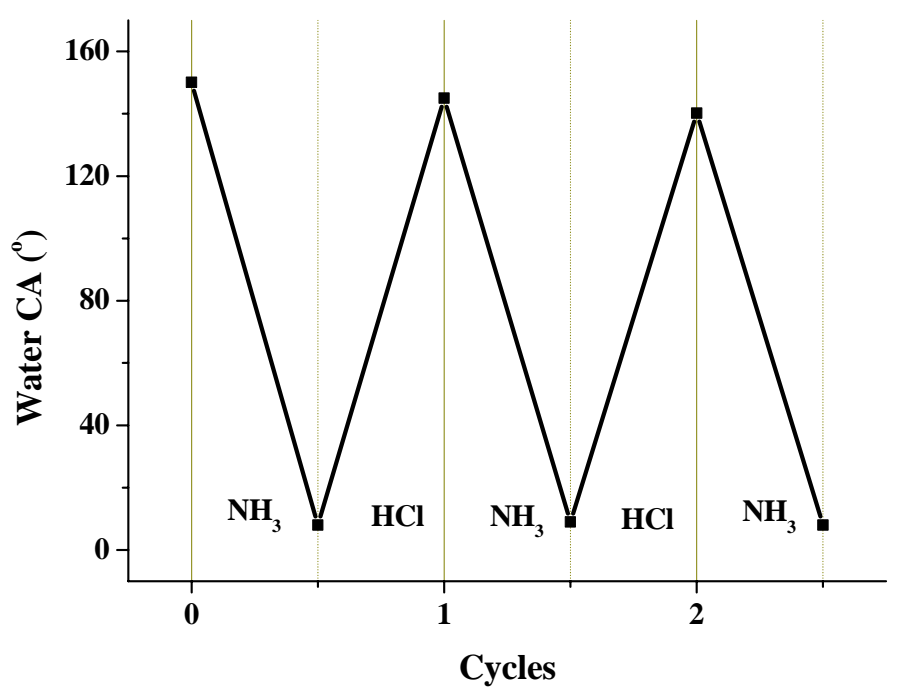

Figure S7: Reversible hydrophobicity and hydrophilicity transition of as-prepared films by alternatively exposing in the vapor of $\mathrm{NH}_{3}$ and $\mathrm{HCl}$. That indicates the wettability of the films can be reversibly switched by the vapor of $\mathrm{NH}_{3}$ or $\mathrm{HCl}$. 

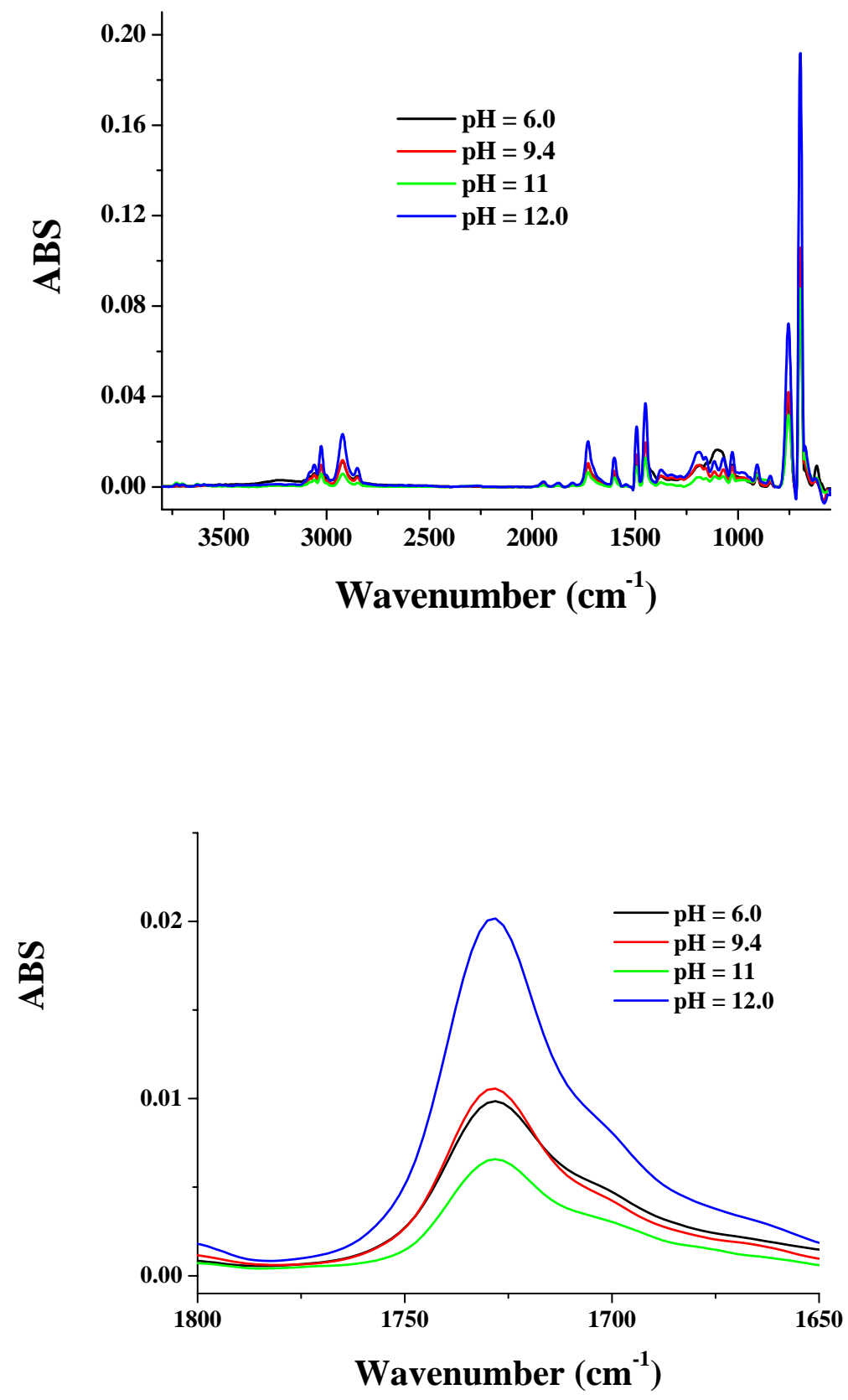


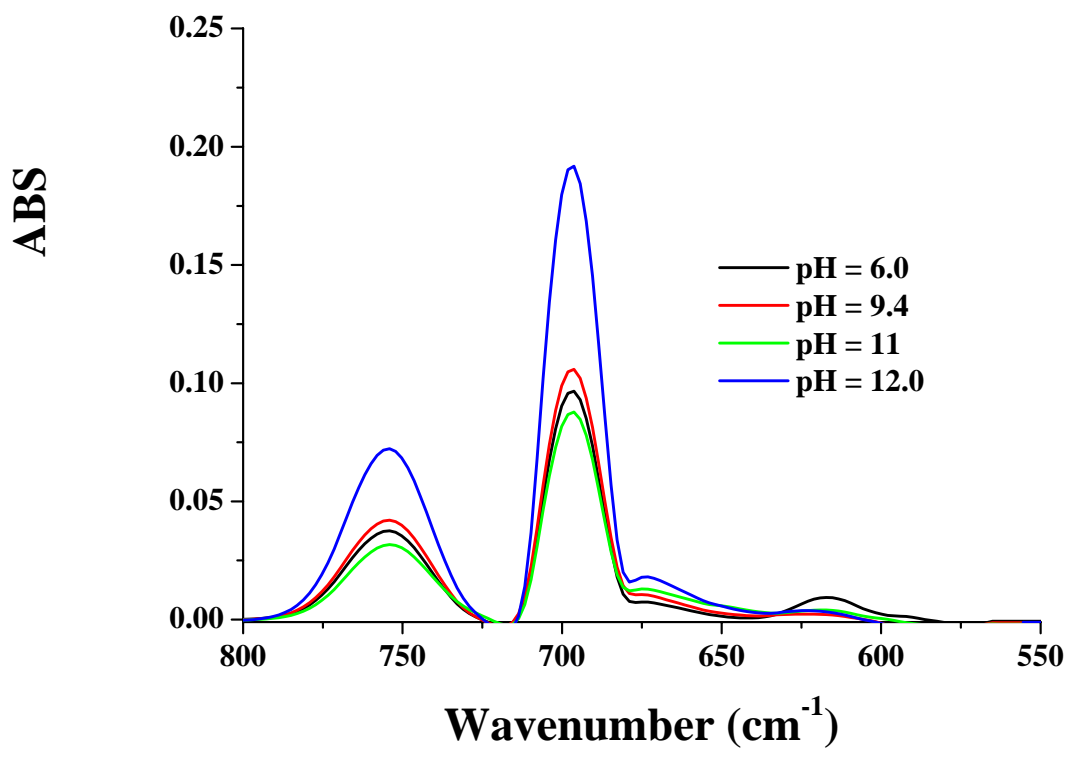

Figure S8: Overview and special bands of ATR-FTIR spectra of the colloidal crystal films when assembled at different $\mathrm{pH}$. The ratios of the $\mathrm{A}_{696} / \mathrm{A}_{1727}$ of different conditions are compared to clarify the change of $\mathrm{C}=\mathrm{O}$ peak strength in Table $\mathrm{S} 2$. 


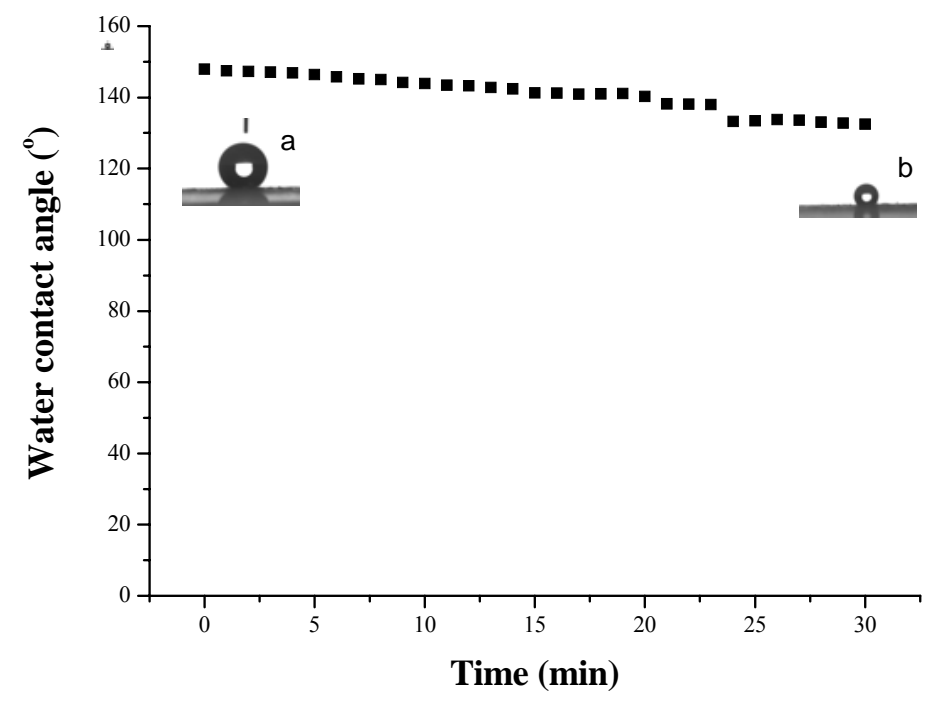

Figure S9: the relationship of water contact angle and time upon the film assembled from latex suspension with $\mathbf{p H = 6}$. The insets are the shapes of water droplet when putting upon the surface for $0 \mathrm{~min}$ (a) and $30 \mathrm{~min}(\mathrm{~b})$, respectively. There is a gradual decrease of water contact angle evolving with time, which is mainly attributed to water evaporation. 
Table S1: The relationship between film water CA and pH of the assembly system

\begin{tabular}{ccccc}
\hline pH & 6.0 & 9.4 & 11 & 12.0 \\
Water CA $\left(^{\circ}\right)$ & $150.4 \pm 0.8^{\circ}$ & $120 \pm 1.2^{\circ}$ & $60 \pm 0.1^{\circ}$ & 0 \\
\hline
\end{tabular}

The result shows that the water $\mathrm{CA}$ of the film decreases with the increasing $\mathrm{pH}$ of the system, also the destroy of the hydrogen bonding between $\mathrm{SO}_{3}{ }^{-}$and $\mathrm{COOH}$ favors the improvement of the wettability of the film, also the decrease of water CA.

Table S2: The change of the ratio $A_{696} / A_{1727}$ with varying assembly $\mathbf{p H}$

\begin{tabular}{ccccc}
\hline $\mathrm{pH}$ & 6.0 & 9.4 & 11 & 12.0 \\
$\mathrm{~A}_{696} / \mathrm{A}_{1727}$ & 9.362 & 9.613 & 9.786 & 9.80 \\
\hline
\end{tabular}

To clarify the change of $\mathrm{C}=\mathrm{O}$ after introducing $\mathrm{NH}_{3} \cdot \mathrm{H}_{2} \mathrm{O}$ into the system, the ATR-FTIR spectra of the films assembled under different $\mathrm{pH}$ are analyzed. Here, the change of $\mathrm{C}=\mathrm{O}$ is compared by he absorbance ratio between the absorbance bands 696 and 1727 $\mathrm{cm}^{-1}$ of the films under different $\mathrm{pH}$ conditions, and the average results of the three experiments at least are presented in Table S2. It could be clearly seen that the $A_{696} / A_{1727}$ ratio increase steadily with increasing $\mathrm{pH}$. That is, there is steady decrease of $\mathrm{C}=\mathrm{O}$ peak due to the $\mathrm{COOH}$ deprotonation to $\mathrm{COO}^{-}$. 